\title{
Research on the Strategies of Improving College Students' Learning Initiative in the Internet Environment
}

\author{
Xiong Yibing, Li Ling, Gao Shutai \\ Jingdezhen Ceramic Institute, Jingdezhen, China
}

\begin{abstract}
In this article, according to the deep needs of college students learning, I used the Internet thinking mode. Then we started college students learning personalized design and customized interactive and intelligent learning methods, and so on. Combined with the "Internet" environment and some related cases, we put forward three proposals: First, strengthen public building, to enhance the learning participation index of college students; Second, strengthen the hardware construction, to improve college students learning ability index; Third, strengthen cultural construction, to enhance the learning of college students happiness index.
\end{abstract}

Keywords: Internet, college students, learning initiative

The Internet has entered a new development situation. With the development of social economy and the upgrading of digital technology, the Internet, mobile phone, TV and other information networks will gradually affect the daily life and learning method. College students are one of the largest groups of Internet users in China. In order to further explore how to enhance the enthusiasm of college students based on the Internet environment and promoting the construction of study style in colleges. We conducted a sample survey of TC university students, and the used the qualitative and quantitative analysis. We take a comprehensive analysis of the results, so it has theoretical and practical significance.

\section{Method}

\section{Research Ideas}

The most important is to strengthen the construction of college study style and the effective integration of the Internet. We can carry out hidden education by through the QQ group, Weibo, WeChat and other methods. Use the "Internet" thinking to extend the traditional classroom. On the basis of adhering to the traditional teaching mode and expand the second classroom (practice classroom), the third classroom (network classroom). So that we can make up for the lack of emotional communication between teachers and students, and meet the needs of student's personalized and diverse learning.

\section{Research Methods}

During the process of the study, I used three kinds of research methods. First is the literature research

\footnotetext{
*Fund Project: The research on improving college students' learning initiative based on the innovation and entrepreneurship environment in the teaching reform project of Jingdezhen Ceramic University in 2015 (No. 007-212050).

Xiong Yibing, master, lecturer, The School of Design, Jingdezhen Ceramic Institute.

Li Ling, master, lecturer, The School of Design, Jingdezhen Ceramic Institute.

Gao Shutai, lecturer, The School of Design, Jingdezhen Ceramic Institute.
} 
method. Reading a large amount of literature and information that are related to the research. In this way, we can understanding the history and current situation of the study on the improvement of students' learning enthusiasm, and provide support for research.

The second method is the investigating method. Every coin has two sides, the Internet is a "double-edged sword”. For college students, learning is not only opportunity but also challenge. The Internet brings more opportunities and challenges for college students, but also provides a reference for the improvement of university study style construction.

The third method is the case summarized method: Being combined with the current academic research on the "Internet", as well as on the study of the construction of academic study. We hope that through the summary of the scholars' excellent educational experience, so that we can put the focus on improving students' learning enthusiasm.

\section{Research Principles}

During the research, we have three principles.

The first principle is the integration of traditional media and new media. Specifically speaking, there are many traditional media in colleges, such as newspapers, radio, lectures, conferences, classroom teaching and so on. Under the modern education idea, we are not going to abandon the traditional media, but to combined the traditional media and new media, use the advantage of the new media, and to build a new model of education in the new media platform.

The second principle is the integration of positive guidance and prevention. With the popularity of the Internet media, we should actively guide students to obtain the necessary information from the Internet, and establish the correct network learning motivation. In the network virtual society, students will encounter more problems and challenges, so the students need to effectively carry on self-discipline and self-management, so that they will establish the network security awareness and learning awareness.

The third principle is the integration of the explicit education and the implicit influence. In this principle, the most important thing is to combine the conscious and unconscious, to carry out a two-way communication by unconsciously influenced, to continuously innovate in working methods, paying more attention on guiding students, and to reform the traditional education mode, paying more attention to the interaction between teachers and students in the new education mode. So that we can change the traditional mode of education into a kind of infiltration education mode.

\section{College Students’ Learning Characteristics Analysis in the “Internet” Environment}

During the process of investigation and study, we issued 271 questionnaires, 267 questionnaires were recovered, among which 263 questionnaires were valid. According to the data of the questionnaire, we analyzed the students' learning attitudes, habits and methods, based on the "Internet” environment. And carry out an in-depth investigation on how to develop the mining of learning resources. Therefore, we believe that the main characteristics of college students based on the "Internet" environment are:

(1) Learning motivation needs to be further excavated. There are $87 \%$ of students said they are using the Internet and other new media, $69 \%$ of the students said they often use the Internet, 35\% of the students said they can use the Internet and the new media to exchange interaction. Study in university is relatively democratic and the learning time is relatively free. In general, students can master the learning content. But to a 
certain extent, the students are easily affected by the virtual network, so the university students learning psychology will easily come to negative situations.

(2) Learning platform is to show a variety of developing trends. Internet era has arrived, students tend to care about social model, social celebrities, star idols and family members or other students in the new media platform, at the same time, they are also interesting in communicating with friends. In the survey, we found that $13.5 \%$ of the students said they would often participate in online discussions, $57.6 \%$ of the students said they would occasionally participate in network discussion, and most of the students said they would like to participate in the Internet based learning discussion, and they have a certain tendency to discuss topics which they are interest in.

(3) Learning methods become diversified. New media era has arrived, we can easily use mobile phone, WeChat and blogs to publish directly personal point of view directly. Compared to the traditional media, its freedom and autonomy greatly improved. To a certain extent, there has been a growing phenomenon of grassroots media from the media, and gradually dilute the elite consciousness. From the survey data, the impact of these new media platforms on college students' ideological influence is gradually strengthened.

\section{Enhancing the Learning Enthusiasm of College Students in the "Internet” Environment}

In our survey, in order to stimulate the learning enthusiasm of the students, TC University construct a new Internet platform through the QQ group, WeChat group and so on.

(1) Insist on holding the annual exhibition of outstanding graduates to promote students to help each other. In the exhibition, the graduating class students to introduce their original content and production process, to share their creative experience, than the lower grade students will ask questions and exchange their ideals, so the exhibition will enhance the interaction of students. In this way, graduates could show their ideas, and the students in the lower grades can learn a lot of creative experience. Therefore, the university is very willing to hold such activities, because this will easily improve student's learning initiative.

Such as in this year, in order to further strengthen the graduates' style display, promote exchanges between students learning experience and to enhance students' learning initiative which based on the "Internet" thinking, TC University held 2016 session of the animation professional and excellent works exhibition in June 2016.

(2) Use two platforms to display the excellent graduation works that major in animation. On the one hand, registered specialized Wechat public platform. On the other hand, the college uploaded students' original works to Tencent video. Through these two ways to promote graduates outstanding works. Among them, Tencent video included more than 20 excellent graduation works. In addition, many of these works have been included in the university graduation collection album, which will strengthen the original and copyright protection.

(3) Select outstanding graduates to participate in high-level professional exhibition. Participate in the competition not only can improve the students' learning enthusiasm, but also can promote the improvement of students' scores, and it will also form a good competitive atmosphere among the students.

\section{Discussion}

We should strengthen "Public building construction", and enhance college students' "Participation index".

(1) Insist on the "heart to heart" work method. In the network environment, the work method of "heart to heart" can strengthen the interaction between students and teachers. This is also an important way to insist the construction about style of study in the network environment, and this is the inevitable requirement to promote 
the educational practice. In addition, there are network survey methods and other communication methods that we can use. And during the theme class meeting, we can form a good learning atmosphere through the "Internet" thinking.

Era is continuing progressing, the contemporary university students learning enthusiasm cannot improve without teacher's supervision. But the university educational environment is different from the senior high school, students have more freedom in university. Combined with the thinking of the Internet, teachers can communicate with students by many new media.

(2) Carry out the "one help one" work method. Use the Internet to innovate the construction of the study style of university, expand the campus network, WeChat group and other college students study style construction positions; Insist on the basic way of combining guidance and prevention. In the complex and ever-changing contemporary society, colleges and universities are also faced with a variety of complex problems. We should establish the "prevention" concept in the usual work.

For example, the classes could held regularly learning experience exchange meeting, inviting outstanding students to introduce their process of growth and learning methods, enable students to further clarify the learning purpose and learning attitude, and it can improve students' learning methods, making them consciously participate in learning. In this way, it will create a superior learning atmosphere.

(3) Develop the common cooperation method. In the current new media, the "Baidu Tieba" is a very good learning platform. In this platform, we can design a new cooperative learning platform, so that cooperative learning is not only between teachers and students, but can also be communicating between students and students. This learning method will strengthen the cooperation between schools and parents, parents can participate in the discussion and release of information feedback in this cooperative learning platform. We should coordinate the relationship between school, society and family, and emphasize the role and function of the school, the society and the family in the improvement of the students' learning enthusiasm.

In the past, because the university study environment is different from the senior high school, the school and the parent connection is not convenient. Many parents do not understand their children's real grades in school. But in the Internet age, schools can easily send an Email to parents, and tell them the students' real situation. This method allows parents cooperate with the school's work, and urge students to study hard at home on vacation.

We should strengthen the "hardware construction" and enhance the learning ability of college students.

The combination of theory and practice: TC University developed a teaching reform program of the studio system. They plan to open a studio in each major from the beginning of the third grade. The purpose is to cultivate students' awareness of the project and team awareness. This can not only improve the students' practical ability, but also can improve teachers' teaching quality and the teaching level.

(2) Integration of traditional media and the Internet. Creating a learning context to stimulate students' interest in learning. This can help students to understand knowledge and acquire skills, and make the students psychological function developed. Making learning activities as a student's initiative and conscious activity. Providing free choice space based on the students' interests and concerns. In addition, we can also develop the network classroom, tap the potential of online education, and allow teachers and students to carry out online reviews and learning exchanges, open and share the real integration of online and offline.

Although the Internet has been developing for many years, but still has great potential. Development of online education has become an inevitable trend. We still have a lot of work to do in network education. We 
can build the network civilization volunteer groups. Through the development of the network civilization volunteer activities, we can promote students I play a greater role $\mathrm{n}$ the service network of struggle work, and lead students to actively participate in the construction of network civilization volunteer service. Therefore, in the future, we can transfer positive energy by this method.

\section{Conclusion}

With the rapid development of science and technology, the human being is facing a new era. Under the background of the whole entrepreneurial environment, that universities should promote the construction of the style of study has become the inevitable demand of the new times. In the context of the current innovation, we need to adopt a modern way to promote the construction of college learning atmosphere. Let the outstanding students to exert their influence, and share the knowledge and practice experience of the university.

In a word, as far as I am concerned, combined with the current situation and according to the problems of some college students in learning enthusiasm, we still have a lot of work to do. Colleges should use the Internet thinking model to strengthen the development of the Internet in many ways. At the same time, take the advantage of new media. And allow students to discuss in the network, than carry out various exchanges and communication in the Internet, so that the construction of network media and learning style will become more attractive. Finally, we can improve the enthusiasm of college students. Although there are some problems in college education, I believe that as long as educators continue to work hard, we will promote the development of Chinese education.

\section{References}

Feng, L. J. (2013). The path of the cultivation of socialist core values. Journal of Beijing Normal University (Social Science Edition), 2013(03), 17-13.

Wang, Z. W. (2016). A study on the influence factors of mobile learning on college Students' learning performance-Based on the cognitive load theory. Donghua University.

Xiang, L. (2014). On promoting the innovation and entrepreneurship education in Colleges and universities. Ideological and Theoretical Education, 2014(8).

Yu L., \& Zhang, G. Q. (2016). The theoretical exploration of moral education of college students in Media Era. Continuing Education Research, 2016(4).

Yuan, W. Y. (2016). The special nature of the socialist core values into the ideological and political course of art institutions and methods. School Party Building and Ideological Education, 2016(06), 49-51. 